\title{
Ethical Principles Underlying the Assessment of Indirect Losses Due to Earthquakes
}

\author{
Jaime García-Pérez¹, Eric García-López ${ }^{2}$ \\ ${ }^{1}$ Instituo de Ingeniería, Ingeniería Estructural,Edif 2, Universidad Nacional Autónoma de México, Ciudad Universitaria, \\ Coyoacán, CDMX, México \\ ${ }^{2}$ National Institute of Criminal Sciences, Magisterio Nacional 113, Tlalpan, CDMX, México \\ Email: jgap@pumas.ii.unam.mx, eric.garcia@inacipe.gob.mx
}

How to cite this paper: García-Pérez, J. and García-López, E. (2021) Ethical Principles Underlying the Assessment of Indirect Losses Due to Earthquakes. Open Journal of Civil Engineering, 11, 179-199. https://doi.org/10.4236/ojce.2021.112012

Received: April 21, 2021

Accepted: June 5, 2021

Published: June 8, 2021

Copyright $\odot 2021$ by author(s) and Scientific Research Publishing Inc. This work is licensed under the Creative Commons Attribution International License (CC BY 4.0).

http://creativecommons.org/licenses/by/4.0/

\begin{abstract}
The reliability optimization process in earthquake engineering requires that the expected present value of the total cost is minimized, including the initial cost as well as the damage costs caused by earthquakes, which include indirect costs. One of these costs is concerned with how much society is willing to invest for preserving human life. Ethical principles, on which to base the assessment of this cost, are presented and discussed in this work. Individual and social values are analyzed. Finally, an optimal seismic design coefficient with the results obtained is calculated for a site with low seismicity.
\end{abstract}

\section{Keywords}

Reliabilities, Utility, Indirect Losses, Decision-Making, Seismic Coefficients

\section{Introduction}

In some cases, we can take the lower limit set by a socially acceptable risk to calculate structural reliabilities. In other cases, we have to calculate the optimum reliability. The latter requires that the social cost of non-monetary values be computed. Among these values, we have the value which society is willing to invest to preserve human life and other intangibles, especially social impact.

In a seminal work, Rosenblueth [1] mentions the concepts on which to base the assessment of how much society should invest to preserve life. These concepts are based on a relativistic, softened utilitarianism that pays heed to utilitarianism of the rule. The author defines utility as a logical scalar measure of the intensity of happiness, and he calls it felicity. This is the form of utility he proposes to maximize. In this paper, Rosenblueth establishes a lower limit to the social value of an anonymous life. He also finds that the value per anonymous life 
depends on the number of victims, the expected present values of individual utilities, their derivatives with respect to the expected present value of income, personal impact, impact on kin and friends, social impact, funeral costs, and foregone production minus expenses and decrease in the quality of life of the rest of society. In 1992 Rosenblueth [2] computes how much society should invest to preserve life. First, he uses the human capital approach, which results amounts to taking the social value of a human life equal to the expected present value of the person's contribution to the gross domestic product during the rest of his/her life. Then he uses the person's utility curve per unit time as a function of time, in order to compute the value of a person's life to himself or herself. Finally, he proposes ethical considerations based on relativistic utilitarianism to calculate how much society should invest to preserve life. Rosenblueth finds that the values computed by using utility curves always exceed the human capital result.

Based on the work done by Rosenblueth [2], García-Pérez [3] computes the expected present value of the person's contribution to the gross domestic product during the rest of his/her life, by using data from Mexico. In 2019 García-Pérez and García-López [4] propose a model to compute the value of the investment society should be willing to make for saving lives. They analyze both individual and social problems. By using two utility curves based on the wealth of an individual, they estimate the value of human life when dealing with small risks such as earthquakes. The authors place more emphasis on methodological aspects than on obtaining precise values. They also make an application to find optimum seismic design coefficients at a low seismicity site.

In this paper, we present and analyze the different ethical concepts on which the utility approach used in the studies mentioned above to compute the indirect losses due to earthquakes is based. We start by establishing an ethical framework and discussing all the principles that comprise it. Then the welfare function as well as individual and social values are discussed. Finally, we compute the minimum values to invest for preserving life and apply them to compute a seismic design coefficient for a low seismicity site.

\section{Decision-Making}

When we make a decision, it is necessary to follow these main steps: we list the alternative decisions that we wish to compare. Then we identify the set of the consequences that each one of these decisions will cause. After that, we establish a measure of the preference that the set of consequences will have, derived from each possible decision, and finally, we choose the decision having the maximum measure of preference. The first two steps can be very complex and they are an important part, which have great formality and are scientifically well founded. They are also morally neutral. On the other hand, the last two steps imply and require a moral context. Therefore, all these concepts belong to ethics. A decision can be moral, just, both or none. It is moral if and only if it is good, it is just if and only if in case of not adopting the decision, it is decided unjustly. 
In order to find optimum seismic design parameters in earthquake engineering, we must minimize the total expected present value of costs, including initial cost, maintenance, and damages caused by earthquakes. Human lives may lie among the costs due to earthquakes. In order to assess these costs, we may ask how much society is willing to invest to preserve a life. One way to choose the optimum solution is by using a decision-making theory. It is clear that ethics will play an important role in the process. Therefore, we will start by discussing some ethical principles on which a good part of the approaches presented are based.

\section{Ethical Framework}

\subsection{Moral}

The intimate feeling of what is good and what is bad, as when an injustice has been done, was born before man. However, the existence of moral as a doctrine, just like justice as a set of norms to be complied with, had to wait until man had consciousness, self-consciousness, and consciousness of good and bad. Civil law and criminal law were born at the same time as the consciousness of man evolved. The interpretation of the written law began a while after it had been established, but ethics waited a little more. It begins with ancient Greek philosophers, but it is Socrates who shapes it and all western schools of ethics emanate from him.

Moral is what is good. Thus, what is the good? We can look at the question from different angles. One may ask: who establishes what is good? And one may answer, "the others". According to them, good is what benefits them. Good is what benefits others. Another vision may be the one based on the objectivism, which is egoist par excellence, good is what benefits me. Sometimes the two points of view come into conflict, sometimes they are complementary, and they often lead to identical decisions. This is because according to the context, someone can be in a relationship of competition, independence or cooperation with others.

A person answers differently when asked what is good for him/her and what is good for society. He/she differentiates between individual good and common good and the latter has priority, but it does not cancel the former. However, what benefits the person, subgroup, subsystem or system today may not benefit tomorrow. Groups evolve, structures change. A moral law may be meaningless when the subsystem for whose benefit it worked disappears or transforms entirely. A moral is not only relative to the subsystem but also relative to time, and the absolute moral must consider the system from here to eternity.

\subsubsection{Happiness}

We understand by benefiting an individual to increase his/her happiness from now on. Likewise, to benefit a group is to increase the happiness of the group. The happiness of the group must be a function of the happiness of its members. Furthermore, from an ethical point of view, we can define the happiness of a 
group as a linear combination, with positive coefficients, a weighted sum, of the happiness of all its members [4]. If in the sense of diffuse sets, some individuals belong more to the group than others; their happiness must weigh more than that of the others. If we do not know a priori how much each one belongs to a group or if we consider anonymous individuals, then all happiness must weigh the same. On the other hand, we cannot quantify happiness in due of uncertainties and we have to work with their expected values [4]. In conclusion, the good for a group is that which maximizes the sum of the expected values of the happiness of all its members.

We can say that for an individual, the good is what maximizes his/her happiness, and for a subsystem it is what maximizes the sum of the happiness of all its members. These are relative morals. In an absolute sense, moral is what maximizes the sum of happiness of all sentient beings from here to eternity [1].

\subsubsection{Moral Laws}

In the following we comment on some moral laws, which concepts we consider important in the establishment of the ethical framework.

When a human being decides to be part of a society, he/she enters into a contract [5]. He/she promises to comply with the norms of society and its decisions, in exchange for society to respect certain rights of his/hers. Thus, the individual and the common good are united. Rousseau [5] says that a man acts with complete freedom when he decides to belong to society. After that, a part of his/her freedom turns into the freedom of society by making decisions for him/her. The social contract theory gives a partial answer on how to solve conflicts between morals related to an individual, subsystems of different levels of order, and the system. When the individual accepts the contract, he/she consents to setting certain goals leading to the common good, above those ensuring his/hers. The same principle applies when a person joins a club, team, political party, and when a country decides to join international organizations. In reality the individual does not have enough freedom as Rousseau implies for joining or leaving the country in which he/she lives, sometimes not even for choosing a political party, nor countries for abstaining from joining international organizations. Moreover, the implicit part of the contract lends itself to numerous interpretations and it is the most extensive part.

That the search for happiness is the motivation of our actions because we are a result of evolution is confirmed in the idea of Spinoza [6]. For Spinoza, happiness is not the award given to virtue, but the practice of virtue. We feel well when we act well. Weaker than the feeling of acting well is the one of having acted well even if there is enough calmness to reflect on what has been done until then, not during the action or during the decision-making. The motivating force of the practice of virtue is important; if we continue to practice virtue, we will end in indulgence.

The postulate of the categorical imperative [7] accepts being proposed as an axiom subjected to refutation, and not as a dogmatic categorical imperative. We 
can express it as a corollary of what we have discussed here. From a group point of view, we must attempt the maximum sum of happiness given equal weight to all members of the group, including ourselves. If our decision meets with this criterion, it will be independent from the person who will make it. Our decision will be equivalent to a universal norm for the members of the group. Furthermore, if we act rationally, we will build the categorical imperative: we must always act so that we wish that our action will turn into a universal law. No member of the group must be an instrument for an end, but he must be a subject, an end himself. Thus, we have limited the universality to the group whose moral we consider. If we understand universal as that related to all humanity, we choose the moral of human species. If we wish to refer to the absolute moral, we understand universal as that related to the totality of beings endowed with sensitivity.

\subsection{Moral in Decision}

The above paragraphs make it evident that the simple statement of the supreme good as the maximization of the sum of happiness of the members of the group, and then by doing nothing else, will lead us into a trivial reductionism. There are values which, not because they are instruments to increase happiness, are no longer important. Even they do not deserve to be seen as goals in themselves. Freedom is one of those. So are power, the ability to create and enjoy beauty, the ability to learn, and the list is endless.

In light of relative morals of growing universality, the good for the individual is what maximizes his/her happiness. And the good for subsystems is what maximizes the sum of happiness of its members, and in light of absolute moral what maximizes that sum for the whole of human beings. If that is the good in each case, the best is that corresponding to a superior hierarchy, and the optimum is that determined by absolute moral. Each relative moral will be subject to the other. In trying to give an answer to the nature of moral, we have posed a vast number of extremely complex problems. We do not expect to solve not even one of them here. For the intended purposes here, we will consider what has been said as enough.

\subsection{Justice in Decision}

Much of the following material is written based on Rawls [8].

A decision is also just when it respects what has been compromised, because the interests of sentient beings can be affected. However, the compromised clauses must be agreed upon before setting up the options. When we say that the criteria accorded will be respected, it means that we do not take into account other criteria except for those compromised, and we do not recognize other interests. An agreement that is always implied is the one to obey the Natural Law, which has a great number of clauses on attributes to be taken into account. If only one attribute is recognized, whatever it is, the remainder of the Natural Law is breached. For many people, the concept of Natural Law is irrelevant. However, it is important 
to conceive it as the minimum set of necessary norms for living together. They are a set of norms that allow us to read a set of rights, the most innate; the rest are inevitably acquired at early ages. Among such rights are the right to live and the right to be treated equal in equal circumstances.

When some simplifications have been made, some forms of justice have arisen such as: The equitable, libertarian, egalitarian, Marxist, meritocratic, social gratitude, etc. Without exception, persons and states are governed by combinations of these forms and by many more. Many objections can arise when we intend to apply one of these forms. Moreover, in some extreme circumstances, some utilitarian criteria unrelated to the forms of justice are applied, for example the practices of triage. There are different criteria among those who instantly decide during the action when human lives depend on their decisions.

Each form of justice admits different variations, and this will be reflected in the way to deal with the problems to study. If human life is the concept that must be treated as equal, the same value to all lives will be given. If it is the time of life, each year will be given the same value, irrespective of who lives it. If it is the possibility of enjoying life, the answer will be different, and so on. Similarly, each one understands something different by necessity.

It would be impractical to assess the value of human life taking into account all the forms that have been mentioned here, among other reasons, because of the problems that we are interested in, there is not enough information. Instead, it is advisable to proceed according to a utilitarian moral, by giving weight to the impacts that produce a death in the person, in their close relatives, and in society. Thus, it is expected to establish a practical, completely sufficient, and realistic approach.

\subsection{Moral-Justice Relationship}

Moral and justice are two characteristics of a single concept. Justice looks to the set of norms which, if obeyed, will allow essential coexistence for maximization of the sum of happiness of those belonging to the group. Moral looks directly to the maximization of the sum of happiness. Injustice necessarily violates a predicted pattern of behavior; evilness may not violate any. If moral principles on how to act of each sentient being and their particular circumstances were codified, then moral would become justice. If the circumstances mentioned in the agreement, which determines when a decision is unjust, were thoroughly analyzed, then justice would agree with that moral. However, this would not be practical. Agreements and norms must have enough of a level of universality to be easy to manage, and specific cases are so unpredictable that it prevents their codification. The meeting point between moral and justice must remain in the field of the hypothetically possible.

\subsection{Normative Ethics}

Rosenblueth [1] says that the decision-maker must act as if he could become any 
one of the subjects for whom he decides. This is a moral principle coming from the objective of maximizing the sum of happiness of all members of the group, and that leads to norms that will define what is unjust and, hence, what is just. Rosenblueth adds that the probability of turning into a member of the group must be equal to that of becoming any other member, and that decision-making must be based on the axiom of Von Newman and Morgenstern [9]. From here he concludes that one must maximize the sum of the utilities of the members of the group. This principle can be obtained from less restrictive conditions, whose nature we will delve into when discussing the kind of consequentialism named utilitarianism.

We find references of utilitarianism that date back to ancient Greek philosophers, and more clearly to Socrates and Aristotle. In its modern version regarding maximization of happiness, utilitarianism begins with the works of Bentham [10]. This moral law was improved by many philosophers such as Stuart Mill J., Sidgwick H., Hare R. and Singer P. Utilitarianism remained at a level of good wishes and general guidance while it was not possible to assess utilities. The change came with the masterpiece of Von Neumann and Morgenstern [9]. After this work, an important number of contributions with a realistic approach began.

It is necessary to formulate utilitarianism in terms of utility as happiness, so that its application makes sense in ethics as well as in rational decision-making. Moreover, it must admit the effects on the utility of both processes and implementations of decisions and all possible consequences, whether intentional or not, material or not, as well as making interpersonal comparisons.

\section{Utility}

The effects of the decision-making process itself on utility show unique characteristics. Utility depends on how detailed the process is carried out. The more information attained, processed and comprehended, and the more options created and examined, the better the decision made, but the more expensive and delayed the process. The study leading to designing or choosing the optimum process of decision-making is a metaprocess. At the same time, the metaprocess should be optimized. The chain could not have ended. It is clear that it must sometimes be stopped because limits to the benefit obtained from new analysis are set up.

Now, utility is an a priori measure while felicity is an a posteriori utility. In decision-making, the expected value of felicity is a preposterior utility. Utility measures the intensity of desire, and felicity measures intensity as it is preferred to have experienced a state. In decision-making, the expected value of felicity is the expected value of intensity, as a person would have preferred to have experienced [1] [4].

\section{Social Welfare Function}

When economics deals with social decisions, it refers to nonmarket decision- 
making, that is, the application of economics to political science. The corresponding normative theory postulates that man is egoistic, rational, and a utility maximizer. In 1938 Bergson [11] published a seminal work on certain aspects of welfare economics, then it follows Arrow's classic contribution in 1951 [12]. From then on, literature has grown extensively on the topic, always in search of a social welfare function that has to be maximized normatively. Arrow [12] postulated a set of axioms regarding the conditions that a social welfare function must meet. He demonstrated that it is not possible to build a social welfare function that satisfies all the axioms by just using information about the preferences of members of society. The following studies have looked to establish ways to obtain a social welfare function using additional information. This information takes into account preference individual intensities directly or indirectly, that is, individual utilities. In 1979 Harsanyi [13] showed that the social welfare function is necessarily a linear combination of the utilities of those forming society.

The aforementioned works have important limitations to be normative from an ethics point of view. The first limitation is the excessive stress on material values. However, this can be overcome. Furthermore, the lack of an appropriate formulation is another limitation in order to take into account the variable time and the restriction of a relative moral valid in the environment of a group of human beings.

\section{Explicit and Quantitative Ethics}

Now let us assume first that decisions that we make just affect the happiness of a sentient being of the universe. A decision will be good if it increases that happiness. The one that maximizes it will be the optimum decision. Now, suppose that the members of a group of sentient beings do not change their respective happiness as a consequence of variations on the happiness of others, either because they ignore these variations or for any other reason, and that our decisions can directly affect the happiness of one or more members of the group and nothing more. Then the optimum decision will be the one that maximizes a certain function of happiness of all members of the group, but in order to be optimum in the previous conditions with respect to the happiness of each member, it needs to be a linear function of the happiness under study. Therefore, we must maximize the utility function: $U=\sum_{i} \alpha_{i} U_{i}$, where index $i$ refers to the $i$ th member of the group. The sum includes all members, $\alpha_{i}$ is the ith weighing factor, necessarily positive, and $U_{i}$ the utility (happiness, felicity) of the ith being. In order to introduce the variable time, we consider each segment of the life of the ith being, comprised between instants $t$ and $t+\mathrm{d} t$, as an individual. Proceeding as before, we conclude that we have to maximize $U=\int_{0}^{\infty} \sum_{i} \alpha_{i} f_{i} \mathrm{~d} t$, where $\alpha_{i}=\alpha_{i}(t)$ is a weighing function and is of the form $\alpha_{i}(0) \mathrm{e}^{-\gamma t}$, where $\gamma$ is a discount rate appropriate to future felicities, $f_{i}=f_{i}(t)$ is the felicity of the $i$ th being by unit time and time is measured from the current instant. As long as we cannot exactly predict the effects that our decisions will cause on the felicities of the members 
of the group, we must write the utility in the following form [1]:

$$
U=E \int_{0}^{\infty} \sum_{i} \alpha_{i} f_{i} \mathrm{~d} t
$$

where $E$ is the expected value. This equation considers the possibility that we do not exactly know the number of members of the group. The felicities of individuals not belonging to the group do not appear explicitly in Equation (1). They manifest themselves insofar as they affect the felicities of the members. On the contrary, this equation explicitly includes the felicities of future generations whose members may belong totally or partially to the group. It is possible to represent a wide range of morals with Equation (1) by adopting different values for the weighing function. These morals could go from egoism to altruism and going through egalitarianism. If goodness is an intrinsic element of morality $\alpha_{i}>0$ must always be used. If the moral system is to reflect the categorical imperative of Kant [7], then $\alpha_{i}$ must be constant for all human beings.

The form of this approach fits into act utilitarianism. In this utilitarian theory, the goodness of each decision is judged in exclusive terms of the direct consequences and, if desired, the effects of decision-making processes on utility are taken into account. There is another utilitarian theory, rule utilitarianism, which seeks to maximize the utility of an individual under the assumption that everyone acts like him/her. Although on a smaller scale, the dilemma between these two theories is similar to that between moral and justice. The solution of the dilemma is given operationally by adopting rule utilitarianism, but allowing exceptions that convincingly lead to act utilitarianism. The norm is rule utilitarianism. The exceptions ordered by act utilitarianism must be justified. It is appropriate to consider the enshrinement of human life in this frame rather than disregarding it, no matter how unhappy a person is, because it violates rule utilitarianism and works against the respect of all forms of life; furthermore, it betrays our inborn aversion to death.

In the above sections we have defined relative and absolute moral. These definitions are in fact axioms because by saying what is good, we imply what our duty is and how we must decide. If we rebuild this theory in reverse order, we meet the conditions so that the theory is objective and valid. If we accept them, we can follow the reasoning that leads us to point out ways to reconcile different relative morals, these with the absolute moral, the rule utilitarianism with that of the act, and the moral with justice. Of course the topic is open, valid, current while humankind exists. In the meantime, a possible answer has been proposed to deal with the problem concerned with this study.

\section{Utility Discount}

It is customary to convert a future utility into its present value by multiplying it by a discount function. This practice could apparently go against a moral principle which postulates that the importance of happiness of a human being must be independent of the moment in which he/she experiences it, even of the generation to which he/she belongs. Even though by accepting this principle, the 
probability that an event happens and destroys the human race is finite and increase with time [14]. Moreover, the probability that the scale of values of a human being differs from now increases with time. Instead of taking into account such possibilities, it is advisable to introduce a discount function. On the other hand, we often give more importance to what is closest in time and to the present generation than to the next one. The same factors influence the banking and business activities that are affected by an interest rate or by an update. Except for small fluctuations, this rate remains constant through some years. Therefore, it is possible to introduce a discount function that can be of the form $\mathrm{e}^{-\gamma t}$, where $\gamma$ is a discount rate usually taken as $0.05 /$ year.

\section{Individual and Social Values}

The problems in which we are interested may be grouped into two types: individual and social. In the first type of problems, the value of a life of a human being may be inferred from what he/she should be willing to pay for reducing the risk of dying or what risk he/she should be willing to accept in exchange for compensation. In the assessment of the individual value of a life free of moral considerations, the verb should is understood as what a rational person would do. In the moral sense, the verb should is understood as a fulfillment of a relative moral when the topic is judged from the point of view of a subsystem of sentient beings, and from an absolute moral when it is from a point of view of the system of all sentient beings. From the individual point of view, we find a coincidence between the sense of duty as rationality and as a relative moral. In the second type of problems, it is a requirement of moral character that the decision-maker puts himself in the circumstances of each member of society. This same conclusion is achieved for the social utility function if this criterion is applied instead of a moral utilitarianism, and if the social contract is adopted as well. Assessment of the value of human life requires knowledge of the shapes of the utility curves in terms of the wealth and income of the persons in whose lives we are interested. These curves $U=U(W)$ are based on wealth plus the expected present value of income. $W$ must satisfy certain conditions as shown in the Appendix. García-Pérez and García-López [4] describe a conceptual and theoretical model in order to assess how much society is willing to invest in preserving a life, discuss individual and social problems with the willingness to pay and accept approaches, and they also present some utility curves in terms of wealth.

Individual human value depends on the following concepts: the utility curve of the person in terms of his/her income or wealth, the utility curve for what the benefits represent to the person that his heirs will receive when he dies, the personal impact of the perspective of dying and of the process of dying in what concerns the person himself. On the other hand, the value of human life for society depends on: the utility curve of the person in terms of his income or wealth, the concepts taking part in the human capital approach, the disutility coming from the fact that there is one more inhabitant in the country, the personal and 
social impacts due to death, and funeral expenses.

\subsection{Bequests, Insurance and Funeral Expenses}

These factors and their influence on the value of human life require a study in the light of both prevailing attitudes before the practice of saving and prevailing behavior patterns, as well as on the psychological implications of establishing bequests and buying life insurance policies. Surely the loss of utility due to the time invested and suffering for participating in funerals is not significant. However, it is worth establishing bounds well justified regarding this concept.

\subsection{Utility Curves}

Utility curves are in function of several variables, even for the same person, and they evolve with time in stationary external circumstances. We assume that the components of utility are additive. The hypothesis of additivity of the utility coming from incomes and consumption and those due to other factors are not necessarily precise enough. In order to know its limitations and its implications of the interaction and no additivity of utilities as dependent on several variables, it is necessary to establish these curves based on combinations of incomes or consumption and other relevant variables. It is also necessary to define the shapes of utility curves, as well as their maximum ordinates. Moreover, it is important to establish the utilities coming from non-economic factors, particularly of the joy of the mere fact of being alive. This could be inferred from Delphi exercises and ex-post studies.

Utility in the current situation is the result of the following concepts: utility coming from economic factors, utility as felicity caused by non-economic factors, and the disutility coming from the anguish of the possibility of dying. In the former, we can consider utility coming from consumption in exchange for spending, utility coming from the amount of money bequeathed to relatives, and utility from the benefit that those relatives will receive from a life insurance.

\section{Utility Coming from Non-Economic Concepts}

Neither we do have objective methods nor is it possible to obtain quantitative information from questionnaires to evaluate these concepts. Let $U(W)$ be the utility associated to income $W$, by unit time or in present value including wealth, $W_{\min }$ the value of $W$ that is required to survive and $U_{\min }=U\left(W_{\min }\right)$, with the convention that the maximum possible value of $U_{\max }=1$ and that $U(W)=0$ if $W<W_{\min }$. By accepting that utilities are additive, $U_{\min }$ is the utility coming from non-economic concepts, as a fraction of the maximum possible utility, when the person is neither before the immediate perspective of dying nor the death of his loved ones. $U_{\min }$ is then the utility, in the sense of felicity, enjoying the fact of being alive, free cultural experiences, contemplating the sunset, being in good company, feeling religious and intellectual experiences. One way to quantify $U_{\min }$ is by presenting a person whose resources just exceed $W_{\min }$, the option of participating in a lottery with probability $p$ of winning and being able 
to spend or give money without limits and probability $1-p$ of dying in a short time. By varying $p$ until it reaches certain value, let's say $p_{1}$, for which the person is indifferent between its current situation and the lottery, we could find $U_{\min }=p_{1}$. And finally one may interpret $U_{\min }$ as a subjective measure of the relative importance of non-economic values with respect to the combination thereof and economic values.

The requirement for $U$ having a finite value in $W_{\min }$ is based on the informal opinion of experts who have thought about the problem [15]. There are those who think that when incomes are so low that a person barely survives, he/she is unable to enjoy anything at all, thus, it should be taken as $U_{\min }=0$. However, consensus supports the hypothesis that, except for the near proximity of $W_{\min }, U$ must be finite and not insignificant. It is customary to appreciate more non-economic values than economic ones. If $W_{\min }$ is null, most people with low incomes from surveys would answer that their degree of happiness and satisfaction would be almost null, but in many cases they estimate that they are happy irrespective of income [16]. Economic values are less important when we can enjoy other values such as cultural and satisfaction in our job.

\subsection{Impacts}

We can use ex-post studies, surveys on preferences among different alternatives, lotteries of a conceptual type, Delphi exercises, to establish relative values among impacts. These impacts can be measured in the victim, his close relatives and the rest of society facing both the possibility and the process of dying. After this we can compare the corresponding disutilities and utilities due to other concepts, including the utility of the joy of the mere fact of being alive.

\subsubsection{Personal Impact on the Victim}

Since we present an explicit treatment of the utility curves in this work, it justifies that we include just the non-economic concepts under the concept of impacts, which are not taken into account by these curves. In this convention, the dichotomy remains between personal impact and social impact. Both impacts are conditioned by our natural aversion to death. The personal impact is about the angst of the person who is going to die and the pain that his close family feels. It is advisable to consider the personal impact comprised by these two concepts: impact on the victim and impact on his close family.

\subsubsection{Social Impact Based on the Number of Victims}

The way the magnitude of social impact varies in function of the number victims and the cause and circumstance of their deaths will require an opinion poll and the participation of experts [17].

\subsubsection{Social Impact Compared with Personal Impact}

It is worth remembering that the meaning we give to the impact excludes the economic losses for the victim (because the person cannot continue to enjoy con- 
sumption), his close family, and society. It also excludes the loss of utility for the victim because he/she is deprived of the joy of living and other non-economic sources of his/her potential happiness. What it includes is strictly non-economic and results from our inborn aversion to death. Therefore, the personal impact is taken as the same for all persons and proportional to the number of victims. However, the social impact is a consequence of familiarity that society has had with the victims. In some situations, it is possible to correlate impact with incomes. From a certain point of view, it is disgusting that social impact keeps some relation with economic incomes of the victim (through its correlation with the importance of the person who dies), but our intention is not to express what the wish is of the supporters of one or another ideology, but what is descriptively the feeling of society.

\subsection{Voluntary and Involuntary Risks}

Personal and social impacts due to death by performing an activity involving risk consciously and voluntarily are usually smaller than when the cause of death is the unavoidable performance of certain activity or when the risk is unknown. We call fatalities of the first type death voluntary risk, and those of the second type involuntary risk.

\section{Minimum Values to Invest for Preserving a Life}

\subsection{Without Considering Bequests and Insurance}

In order to find a family of utility curves that meets all requirements, it is necessary to carry out surveys among a population and use Delphi exercises. Because the parameters of the expressions will surely vary greatly from person to person, it would be impractical to try a statistical analysis of the data collected. In addition, it would not be useful due to great individual differences. It is better to adopt a family of curves, then impose restrictions on the parameters and find the combination of parameters that give the smallest possible value on human life. This would provide guidance on individual decisions. Furthermore, because the values that we will compute will be significantly greater than what we use in a country, a reliable lower bound will be more credible than that of a set of possible figures subject to visible uncertainties.

García-Pérez and García-López [4] propose a utility function based on previous works by Keeney and Raiffa [18] and Howard [19].

$$
U(W)=\left(1-\alpha \mathrm{e}^{-a \delta}-\beta \mathrm{e}^{-b \delta}\right) U_{\max }
$$

where $\alpha, \beta, a, b$ are constants, $U_{\max }$ is the maximum possible utility, assuming that we do not have any economic restriction, and $\delta=\left(W-W_{\min }\right) / W_{\min }$ is the normalized net wealth.

\subsection{To Individual}

The value of human life, when dealing with small risks and considering the dis- 
utility associated with experiencing death, may be obtained from Rosenblueth [1].

$$
L=\left(U+I_{p}\right) / U^{\prime}
$$

where $I_{p}$ stands for the net personal impact should the person not die as a consequence of the decision being analyzed, that is, if the person should die what we would call a natural death. Rosenblueth [1] quantifies the net personal impact approximately as $U_{\text {min. }}$. Figure 1 shows this value.

The conditions shown in the Appendix require satisfying the following equation $\alpha+\beta=\left(U_{\max }-U_{\min }\right) / U_{\max }$ and inequalities $\alpha a+\beta b \leq\left(U_{\max }-U_{\min }\right) / U_{\max }$ and $\alpha, \beta, a, b>0$, and we adopt the convention $a<b$ because it is necessary that $a \neq b$. These expressions are associated to Equation (2). Quotient $U_{\min } / U_{\max }$ represents the relative importance of non-economic factors with respect to the maximum possible felicity for the person, that is, the ordinate of the utility function normalized in $W=W_{\min }$. We will write this quotient as $U_{\min } / U_{\max }=1-\alpha_{1}$. It can be demonstrated that the condition for $L$ to be minimum when it is given by Equation (3) and Equation (2) rules makes $\beta=0$, and $a \leq 1$. Then we get

$$
U(W)=\left(1-\alpha_{1} \mathrm{e}^{-a \delta}\right) U_{\max }
$$

where $0<a \leq 1$. We may adopt this expression not because it is a good approximation to the utility curves of most persons, since it violates the condition of decreasing aversion to risk (implicit in $\alpha, \beta, a, b>0$ ), but because it gives a lower bound to $L$. By substituting in Equation (3) we find

$$
L=W_{\min }\left[\left(1+I_{p} / U_{\max }\right) \mathrm{e}^{a \delta}-\alpha_{1}\right] / a \alpha_{1}
$$

where a may be found by deriving Equation (5) with respect to a, and making equal to zero.

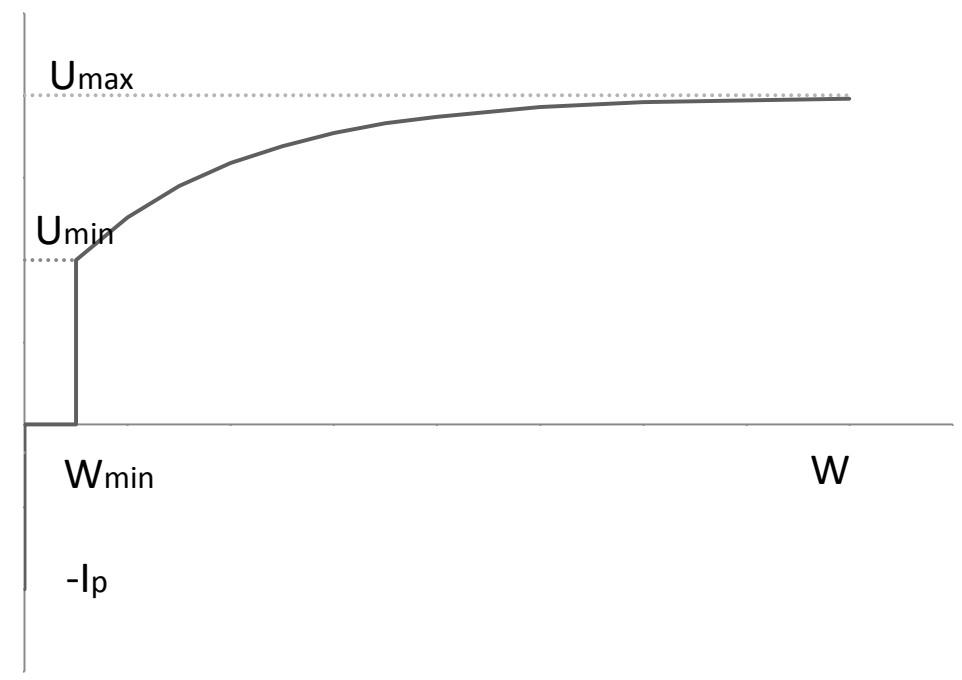

Figure 1. Utility curve. 
It is worth noting that the utility curve $U$ in function of $W$ computed this way, with $a$ in function of these quantities is not exactly a utility curve in the sense that we have expressed here, but each value of income or wealth corresponds to a different curve and the one obtained like this is the locus of the points indicating the utility of different persons, each one of them with the income or wealth that he/she currently has. Of course a model is desirable in which a utility curve corresponds at each instant. If the expected income does not change, the curve evolves in time, but for the time being, we will be satisfied with the minimum value of $L$.

We estimate $L$ for Mexico by using Equation (5). The expected present value of the minimum subsistence is inferred from mortality rates data taken from Mexico's Census Bureau (INEGI-2020) [20], which turns out to be $W_{\min }=45450$ US dollars. We also consider $I_{p}=U_{\min }, U_{\min } / U_{\max }=0.5$ [1], $a=1.1$, $W / W_{\min }=1.7$. We consider a $25 \mathrm{yr}$. old person and a discount factor of $0.05 / \mathrm{yr}$. The value is $L=232250$ US dollars.

\subsection{To Society}

We have postulated that the decision-maker must put himself in the circumstances of each member of society with a probability or a weight factor proportional to the degree of belonging of the member to society, thereby satisfying what has been established in a social contract, as well as the criteria of justice and the relative moral to the group in question. The decision-maker must encourage that a relative moral to larger groups of which the society he/she serves is a part be adopted; and above all relative morals, absolute morality, which gives equal weight to all sentient beings must be adopted. Therefore, we will give the same weight to felicity of all persons.

When the decision-maker must proceed as if he had the same probability of putting himself/herself in the circumstances of each member of society, the welfare function becomes the sum of individual utilities. Regarding a person's life, there are some components comprising his affection in social utility, including himself/herself as part of society: the felicity or utility of the person himself/herself, the benefit derived from what he/she produces, the disutility that represents one more inhabitant, the disutility coming from personal and social impacts due to his/her death and funeral expenses. To make these concepts comparable, they can be expressed in terms of their expected present values.

The production component can be left out in an attempt to find a lower limit to which the life of each person is worth for society. This component is the only one that indirectly takes into account the criterion of human capital. The utility derived from the fact of living and consuming can be taken as a basis for comparison of other concepts. This utility can be computed from two concepts: the maximum utility that a person is able to experience in terms of his/her age and years of studies, and the amount of this utility corresponding to expected incomes of the person year after year. The disutility to society caused by a person 
occupying another place in the country can be taken proportional to the expected present value of the person's years of life. The disutility due to personal and social impacts is the expected present value of the probability of dying. Furthermore, in the absence of other indices, social impact may be taken as a function of the person's incomes. Both the personal and social impact depend on whether the risk taken by the person is the result of a conscious decision to take it, even if it can be avoided or if it is involuntary. The material funeral expenses represent expenditure as well as a source of incomes and consumption for several persons; therefore, they may be ignored. Instead, it is appropriate to assess the loss of working time of those who attend the funeral.

The social value of a human life of a person $i$ belonging to the group may be computed from the following expression.

$$
L_{i}=\left(U_{i}+I_{p}^{i}+I_{s}^{i}+I_{k}^{i}-A_{i}\right) / U_{i}^{\prime}+F_{i}
$$

where $I_{p}^{i}$ is the personal impact, $I_{s}^{i}$ the social impact, $I_{k}^{i}$ the impact on the victim's kin and friends, and $F_{i}$ the funeral costs. These variables represent net values, that is, after discounting their expected present value should the victim eventually die a natural death. $A_{i}$ is the monetary equivalent of the decrease in the survivor's quality of life for there being one more member in society had the victim lived. Numerical values of variables in Equation (6) may be obtained from surveys, interviews, questionnaires, Delphi exercises, and by examining preferences between different alternatives and lotteries of a conceptual type. Rosenblueth [1] has found that $I_{k} \cong I_{p} / 2$, and $I_{s} \cong 3 I_{p}$. If we proceed as in the individual case and use in addition $F_{i}=5000$ US dollars, and $A_{i}=4 I_{p}$ we find that $L_{s}=190800$ US dollars to society.

As we can see, the social lower bound comes out smaller than the individual one. This could mean that society is willing to invest less in order to preserve a life than the individual does. However, both values are greater than those computed by using human capital approaches. In a previous work, García-Pérez [3] found a value of 45,000 US dollars for a reference age of 25 years. This is due to the fact that human capital approaches take into account the value of money that is received with certain approximations or what is consumed while living, not all the value of staying alive. They leave out what the joy of living is worth, the pleasure that the living individual gives to others and the pain that his death causes them. The approaches also leave out emotional and cultural values.

\section{Optimum Reliabilities}

In civil engineering, it is possible to carry out a formal analysis of reliability optimization for large-scale projects. In some cases, codes and standards or, in their absence, usual practices are used. In these three cases, the engineer or decision-maker is responsible to society for safety decisions.

To make optimal decisions in earthquake engineering, we must quantify the consequences of our decisions. We wish to maximize the utility associated with 
the design of the structural system. The utility function takes into account the benefit resulting from the existence of the system, the initial cost, and the losses implying its possible failure. Among the losses may lie human lives. But how can the decision-maker proceed in the best possible way? Furthermore, how can he find the optimal solution if he lacks the basis to assign values to the most important thing that would be lost in the event of failure, human lives? The decision-maker needs an answer, however debatable it is, or as unacceptable as it may seem to many who judge him. The decision-maker must explain to society what he is committed to and, within his commitments, what value he assigns to human life in his decisions. Society may accept or reject the agreement or request that it be modified.

Now, on what basis will the decision-maker propose the value he will assign to how much society is willing to invest for preserving a life? In a previous section, we mention that the human capital criterion underestimates this value, and that the social value is smaller than the individual one. The decision-maker knows that certain ex-post studies underestimate and others overestimate the value that society assigns to each life. He also has some basis for estimating the difference between what society does and what it should do. Once one or more figures have been estimated, the decision-maker will have to submit them to society for its consideration. If they are approved and if the agreement with society is closed, the professional's responsibility is defined; if not, let him hear from society.

\section{Seismic Design Coefficients}

In this paper we have presented a method for computing a lower value on how much an individual or society is willing to invest in order to preserve a life. One application is the selection of optimum design parameters such as seismic coefficients. A thorough discussion is needed on how the method developed in this work can improve current seismic design initiatives (performance-based earthquake engineering) and thus promote a discussion for practical implementations. This is out of the scope of this work. For the sake of illustration, we will use a simple decision rule including the lower limit computed as an additive value in losses when establishing the objective function. This is explained below.

The approach to compute optimum seismic design parameters was first proposed by Rosenblueth [21] and Esteva [22]. These authors consider that the process of occurrence of earthquakes is Poisson. The initial cost of a structure and the cost due to future earthquakes depend only on the intensity measure, and the system is restored immediately after each failure. The approach considers the optimization of the expected present value of the total cost $z(c)$, which includes the initial cost of structures $x(c)$, and the expected present value of the cost due to future earthquakes $y(c)$, where $c$ stands for seismic design coefficient. Thus, we wish to optimize the objective function.

$$
z(c)=x(c)+y(c)
$$


Based on works done by Whitman et al. [23], Grandori [24], Ferrito [25], Rosenblueth [1], and Vargas and Jara [26], it is reasonable to write the initial cost of the structures as:

$$
\begin{aligned}
& x(c)=C_{1} \quad \text { if } c \leq C_{0} \\
& x(c)=\left[1+\alpha_{2}\left(c-c_{0}\right)^{\alpha_{3}}\right] C_{1} \quad \text { if } c>c_{0}
\end{aligned}
$$

where, if the structure is not designed to withstand earthquakes, $C_{1}$ would be its corresponding cost and $c$ its lateral resistance, $\alpha_{2}$ and $\alpha_{3}$ are constants. Now, the expected present value of the cost due to future earthquakes $y(c)$ can be obtained as Rosenblueth [21], Rosenblueth [27], Rackwitz [28].

$$
y(c)=H(c) v(c) / \gamma
$$

Here $v(c)$ is the exceedance rate of a seismic demand, $\gamma$ is the discount rate representing money in the future and usually taken as $0.05 /$ year, $H(c)$ is the expected present value of losses each time that an earthquake occurs. These losses are the consequences of the failure of the structure beyond its own cost of construction, and are given by $x(c)+s(c)$ [29]. In most cases $s(c)$ is constant, including the direct cost of physical damage and the cost of demolition and removal, as well as the cost of human lives and injuries, thus $s(c)=s$ may be used. By substituting Equations (8) and (9) in 7 and normalizing by $C_{1}$ we get the expected present value of the cost to be optimized. Thus,

$$
\frac{z(c)}{C_{1}}=1+\alpha_{2}\left(c-c_{0}\right)^{\alpha_{3}}+\left[1+\alpha_{2}\left(c-c_{0}\right)^{\alpha_{3}}+\frac{s}{C_{1}}\right] v(c) / \gamma
$$

By using Equation (10), we can compute the optimum seismic design coefficient for a site with an exceedance rate of $v(c)=(0.001 / c)^{r}$, where $r$ depends on site location under study, and for a low seismicity site is given by 1.5 [30]. We also use $\alpha_{2}=0.5, \alpha_{3}=1.3, c_{0}=0.05, C_{1}=10^{5}$ [31] [32], and $s=232250$ US dollars. The optimum seismic design coefficient is $c_{\text {opt }}=0.16$, which is a value in the range reported in the literature for this kind of site [30]. However, inclusion in the objective function of how much society is willing to invest for preserving a life deserves a thorough study.

\section{Concluding Remarks}

Ethical principles on which to base the calculation of how much society is willing to invest for preserving a life have been presented and discussed. The corresponding minimum individual and social values are computed. The latter results are lower than the individual value meaning that society is apparently willing to invest less in preserving life. The results were used to find an optimum seismic design coefficient for a low seismicity site. We need to learn more about the topic, especially utility curves. These curves are in function of multiple variables even for the same person, and they also evolve in stationary external circumstances with time. A model in which a utility curve corresponds to each instant would be desirable. 


\section{Conflicts of Interest}

The authors declare no conflicts of interest regarding the publication of this paper.

\section{References}

[1] Rosenblueth, E. (1987) What Should We Do with Structural Reliabilities, Reliability and Risk Analysis in Civil Engineering. Proceedings of the 5 th International Conference on Applications of Statistics and Probability in Soil and Structural Engineering, Waterloo, Ontario, 24-34.

[2] Rosenblueth, E. (1992) The Social Value of Human Life in Earthquake Engineering. In: International Symposium on Earthquake Disaster Prevention, CENAPRED, Mexico DF, 185-197.

[3] García-Pérez, J. (2012) The Value of Risk Reduction in Optimum Seismic Design. 15 th World Conference of Earthquake Engineering, Lisbon, 24-28, September 2012, 8668-8676.

[4] García Pérez, J. and García-López, E. (2019) Assessment of Seismic Indirect Losses Based on Utility Curves. Open Journal of Civil Engineering, 9, 211-229. https://doi.org/10.4236/ojce.2019.93015

[5] Rousseau, J.J. (1762) The Social Contract (Translated by Bennett, J.). http://www.earlymoderntexts.com/

[6] Spinoza, B. (2001) Ethics. Translated by W. H. White, Wordsworth Editions Limited, Ware.

[7] Kant, I. (2002) Critique of Practical Reason. Translated by Werner S. Pluhar, Hackett Publishing Company, Inc., Indianapolis.

[8] Rawls, J. (1999) A Theory of Justice (a Revised Edition). The Belknap Press of Harvard University Press, Cambridge.

[9] Von Neumann, J. and Morgenstern, O. (1943) Theory of Games and Economic Behavior. 2nd Edition, Princeton University Press, Princeton.

[10] Bentham, J. (1834) Deontology, or the Science of Morality. Edited by Bowring, J., Longman, London. https://doi.org/10.1093/oseo/instance.00077236

[11] Bergson, A. (1938) A Reformulation of Certain Aspects of Welfare Economics. The Quarterly Journal of Economics, 52, 310-334. [reprinted in Readings in Welfare Economics (6, 1969, pp. 7-25)] https://doi.org/10.2307/1881737

[12] Arrow, K.J. (1951) Social Choice and Individual Values. Wiley, New York; Revised Edition, Yale University Press, New York and London, 1963.

[13] Harsanyi, J.C. (1979) Bayesian Decision Theory, Rule Utilitarianism, and Arrow's Impossibility Theorem. Theory and Decision, 11, 289-317. https://doi.org/10.1007/BF00126382

[14] Cropper, M.L. and Portney, P.R. (1992) Discounting Human Lives. Resources, 108, $1-4$.

[15] Linnerooth, J. (1979) The Value of Human Life: A Review of the Models. Economic Inquiry, 17, 52-74. https://doi.org/10.1111/j.1465-7295.1979.tb00295.x

[16] Helliwell, J.F., Layard, R., Sachs, J. and De Neve, J.-E., Eds. (2020) World Happiness Report. Sustainable Development Solutions Network, New York.

[17] Keeney, R.L. (1980) Evaluating Alternatives Involving Potential Fatalities. Operations Research, 28, 188-205. https://doi.org/10.1287/opre.28.1.188 
[18] Keeney, R.L. and Raiffa, H. (1976) Decisions with Multiple Objectives: Preferences and Value Trade-Offs. John Wiley \& Sons, New York.

[19] Howard, R.A. (1979) Life and Death Decision Analysis, Research Report No. EES DA-79-2. Stanford University, Stanford.

[20] INEGI-2020. Mexico's Census Bureau. http://www.inegi.org.mx/

[21] Rosenblueth, E. (1964) Closure to Probabilistic Design to Resist Earthquakes. Journal of the Engineering Mechanics Division, 90, EM5. https://doi.org/10.1061/JMCEA3.0000536

[22] Esteva, L. (1968) Bases para la formulación de diseño sísmico. Ph.D. Thesis, Faculty of Engineering, UNAM.

[23] Whitman, R.V., Biggs, J.M., Brennan III, J., Cornell, C.A., de Neufville, R.Y. and Vanmarcke, E. (1973) Summary of Methodology and Pilot Application, Seismic Decision Analysis, Report No. 9. Department of Civil Engineering, MIT, Cambridge.

[24] Grandori G. (1977) Seismic Zoning as a Problem of Optimization. Proceedings of the 2 nd International Conference on Structural Safety and Reliability, 613-624.

[25] Ferrito, J.M. (1984) Economics of Seismic Design for New Buildings. Journal of Structural Engineering, 110, 2925-2937. https://doi.org/10.1061/(ASCE)0733-9445(1984)110:12(2925)

[26] Vargas, E. and Jara, J.M. (1989) Influencia del coeficiente sísmico de diseño en el costo de edificios con marcos de concreto, Memorias del VIII congreso nacional de ingeniería sísmica y VII congreso nacional de ingeniería estructural. Acapulco.

[27] Rosenblueth, E. (1976) Optimum Design for Infrequent Disturbances. Journal of the Structural Division, 102, 1807-1825. https://doi.org/10.1061/JSDEAG.0004431

[28] Rackwitz, R. (2000) Optimization-The Basis of Code-Making and Reliability Verification. Structural Safety, 22, 27-60. https://doi.org/10.1016/S0167-4730(99)00037-5

[29] Rosenblueth, E. (1976) Towards Optimum Design through Building Codes. Journal of the Structural Division, 102, 591-607. https://doi.org/10.1061/JSDEAG.0004298

[30] Ordaz, M., Salgado-Gálvez, A., Pérez-Rocha, L.E., Cardona, O. and Mena-Hernández, U. (2017) Optimum Earthquake Design Coefficients Based on Probabilistic Seismic Hazard Analyses: Theory and Applications. Earthquake Spectra, 33, 1455. https://doi.org/10.1193/110116eqs189m

[31] García-Pérez, J., Castellanos, F. and Díaz, O. (2005) Occupancy Importance Factor in Earthquake Engineering. Engineering Structures, 27, 1625-1632. https://doi.org/10.1016/j.engstruct.2005.05.017

[32] García-Pérez, J. (2016) Expected Present Value of Losses in the Computation of Optimum Seismic Design Parameters. Engineering and Technology International Journal of Geological and Environmental Engineering, 10, 626-631. 


\section{Appendix}

Adapted from García-Pérez and García-López [4].

\section{Conditions for Utility Functions}

1) $U(W)=0$ if $W<W_{\min }$. This implies that the utility of a dead person is nil. It is arbitrarily imposed and by this we accept either that $W$ includes the total wealth or that there is no unemployment insurance.

2) $U^{\prime}(W)>0$ if $W \geq W_{\min }$, where the prime denotes derivative with respect to $W$. If someone does not wish to receive an amount of money, he/she can donate the excess and remain as before.

3) $U^{\prime \prime}(W)<0$ if $W \geq W_{\min }$, that is, $U(W)$ is concave. People use the first incomes to cover the most urgent needs, thus they are the most valuable, and generally, the value of incomes decreases as wealth increases.

4) $U^{\prime \prime 2}(W)<U^{\prime}(W) U^{\prime \prime \prime}(W)$ if $W \geq W_{\min }$. This is equivalent to say that risk aversion, defined as $-U^{\prime \prime}(W) / U^{\prime}(W)$, must be a decreasing function of $W$. A person, who with a certain wealth is willing to accept certain risks, should be willing to accept the same risks and more with a greater wealth.

5) $U(\infty)=U_{\max }<\infty$. This condition comes from the finiteness of human beings. We are only able to desire with finite intensity. The unit value is often assigned to the maximum possible value.

6) $U(W)>0$ if $W \geq W_{\min }$. Although the misery of some people is such that they would rather be dead than alive, the opposite is also true. 